\title{
Theta-Burst Transcranial Magnetic Stimulation Alters Cortical Inhibition
}

\author{
Alia Benali, ${ }^{1,4}$ Jörn Trippe, ${ }^{1}$ Elke Weiler, ${ }^{1}$ Annika Mix,${ }^{1}$ Elisabeth Petrasch-Parwez, ${ }^{2}$ Wolfgang Girzalsky, ${ }^{3}$ Ulf T. Eysel, ${ }^{1}$ \\ Ralf Erdmann, ${ }^{3}$ and Klaus Funke ${ }^{1}$ \\ ${ }^{1}$ Institute of Physiology, Department of Neurophysiology, ${ }^{2}$ Institute of Anatomy, Department of Neuroanatomy and Molecular Brain Research, and \\ ${ }^{3}$ Institute of Physiological Chemistry, Department of Systems Biochemistry, Ruhr-University Bochum, 44780 Bochum, Germany, and ${ }^{4}$ Department of \\ Cognitive Neurology, Hertie-Institute for Clinical Brain Research and Center for Integrative Neuroscience, University of Tübingen, 72076 Tübingen, \\ Germany
}

Human cortical excitability can be modified by repetitive transcranial magnetic stimulation (rTMS), but the cellular mechanisms are largely unknown. Here, we show that the pattern of delivery of theta-burst stimulation (TBS) (continuous versus intermittent) differently modifies electric activity and protein expression in the rat neocortex. Intermittent TBS (iTBS), but not continuous TBS (cTBS), enhanced spontaneous neuronal firing and EEG gamma band power. Sensory evoked cortical inhibition increased only after iTBS, although both TBS protocols increased the first sensory response arising from the resting cortical state. Changes in the cortical expression of the calcium-binding proteins parvalbumin (PV) and calbindin D-28k (CB) indicate that changes in spontaneous and evoked cortical activity following rTMS are in part related to altered activity of inhibitory systems. By reducing PV expression in the fast-spiking interneurons, iTBS primarily affected the inhibitory control of pyramidal cell output activity, while cTBS, by reducing CB expression, more likely affected the dendritic integration of synaptic inputs controlled by other classes of inhibitory interneurons. Calretinin, the third major calcium-binding protein expressed by another class of interneurons was not affected at all. We conclude that different patterns of TBS modulate the activity of inhibitory cell classes differently, probably depending on the synaptic connectivity and the preferred discharge pattern of these inhibitory neurons.

\section{Introduction}

The increase in cortical excitability following high-frequency $(>$ $4 \mathrm{~Hz}$ ) repetitive transcranial magnetic stimulation (rTMS) and the opposite effect obtained with low-frequency stimulation (Fitzgerald et al., 2006) has been attributed to long-term potentiation (LTP) and long-term depression (LTD) of cortical synapses (Thickbroom, 2007), with reference to the effects obtained with similar stimulation protocols in vitro (Tsumoto, 1992). The recently established theta-burst stimulation (TBS) protocols for rTMS (Huang et al., 2005) are composed of high stimulation frequencies $(50 \mathrm{~Hz}$ bursts of 3 pulses repeated at $5 \mathrm{~Hz}$ ). However, cortical excitability was found to be either enhanced or lowered, depending on the duration of the burst trains applied. It is usually enhanced if 20 trains of two seconds are repeated at $10 \mathrm{~s}$ intervals [termed intermittent TBS (iTBS)], but lowered if a single train of

\footnotetext{
Received March 17, 2010; revised Sept. 24, 2010; accepted Nov. 16, 2010.

The Deutsche Forschungsgemeinschaft (K.F., FU256/3-1), the Federal Ministry of Education and Science, and the Competence Network "Stroke" (K.F. and U.T.E.) supported this work. We appreciate the technical help of Ute Neubacher, Dimitrula Winkler, Angelika Herker-See, Ulrike Freimann, Hans-Werner Habbes, Marlen LöbbeckeSchumacher, and Gabi Bomholt. We further thank Martin Giese, Wolfgang Härtig, Thomas Kammer, and Beat Schwaller for helpful comments on the manuscript. Moreover, we appreciate the gift of anti-Kv3.1b antibody by Wolfgang Härtig (University of Leipzig, Leipzig, Germany).

The authors declare that they have no competing financial interests.

Correspondence should be addressed to Prof. Klaus Funke, Department of Neurophysiology, Medical Faculty, Ruhr-University Bochum, Universitaetsstrasse 150, 44801 Bochum, Germany. E-mail: funke@neurop.rub.de. DOI:10.1523/JNEUROSCI.1379-10.2011

Copyright $\odot 2011$ the authors $\quad 0270-6474 / 11 / 311193-11 \$ 15.00 / 0$
}

$40 \mathrm{~s}$ had been applied [continuous TBS (cTBS)] (Huang et al., 2005). It is thus reasonable to suggest that further mechanisms than LTP of synapses between excitatory neurons contribute to the changes in cortical excitability, most likely changes in the activity of inhibitory cortical systems. Nonadapting, fast-spiking (FS) neurons of the large-basket and chandelier type, as well as multipolar bursting cells, which typically express the calciumbinding protein $(\mathrm{CaBP})$ parvalbumin $(\mathrm{PV})$, determine cortical excitability and synchronization of pyramidal cell output activity via perisomatic synapses (Kawaguchi and Kubota, 1998; Blatow et al., 2003; Freund, 2003; Markram et al., 2004; Howard et al., 2005). Inhibitory neurons expressing other CaBPs such as calbindin D-28k (CB) or calretinin (CR), but not PV, preferentially control dendritic integration of synaptic inputs to pyramidal cells or the activity of other interneurons. These non-FS neurons are further characterized by lower-frequency, adapting regular, irregular, or bursting activity (Markram et al., 2004).

Using two major approaches, in vivo electrophysiology and analysis of protein expression, we tested whether and how cortical inhibition contributes to rTMS-induced changes in cortical excitability. In anesthetized rats, we recorded electroencephalographic activity from the frontal cortex, and multiunit activity (MUA) and somatosensory evoked potentials (SEPs) from layer IV of the primary somatosensory cortex before, during, and after rTMS. Acute $(\sim 2 \mathrm{~h})$ and subchronic $(1,3$, or $7 \mathrm{~d})$ rTMS effects on cortical expression of PV, CB, and CR were determined by immunohistochemistry and immunoblotting in a sham-controlled 
fashion (see Fig. 1; supplemental material, available at www.jneurosci.org, for further details). CaBPs were found to be expressed in an activity-dependent manner (Bender et al., 2000; Lewis et al., 2005; Tropea et al., 2006; Schwaller, 2009; Sun, 2009). Moreover, expression of distinct CaBPs correlates with the temporal characteristics of neuronal spiking activity (e.g., fast-spiking vs non-fast-spiking) and controls short-term plasticity of inhibitory synapses via the temporal dynamics of presynaptic calcium buffering and transmitter release (Caillard et al., 2000). This way, distinct CaBPs like PV particularly contribute to the temporal dynamics of network activity as is supposed for gamma oscillations (Vreugdenhil et al., 2003; Cardin et al., 2009).

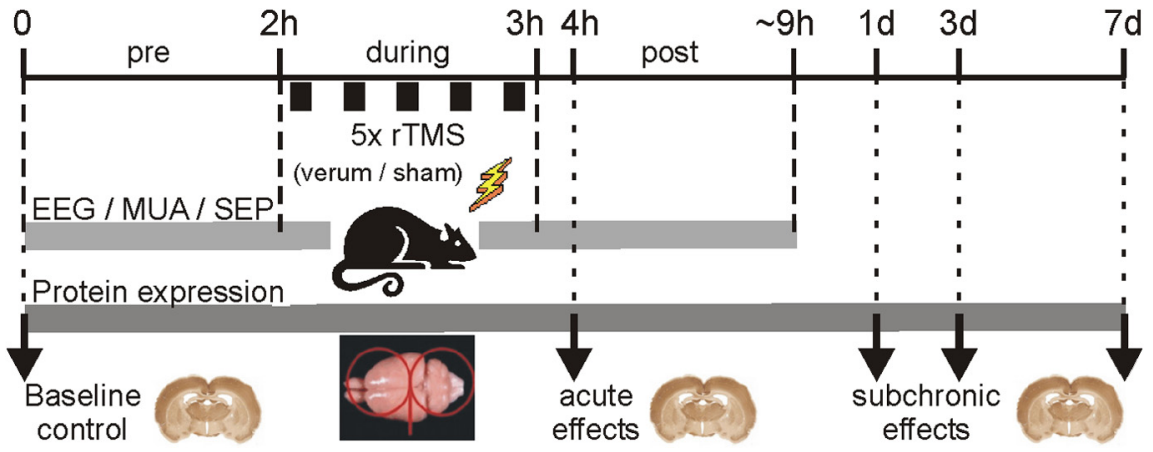

Figure 1. Timeline of the two major series of rTMS experiments. In one electrophysiological series, EEG activity, MUA, and SEP activity was recorded before (pre), during, and up to $\sim 6 \mathrm{~h}$ post-rTMS, with either verum or sham iTBS or cTBS applied to the rats. In case of the molecular-biological/histological series, four different time points following rTMS were investigated: $2 \mathrm{~h}$ (acute), and 1,3 , and $7 \mathrm{~d}$ (subchronic) post-rTMS, with groups receiving either verum $1 \mathrm{~Hz}$ rTMS, iTBS, or cTBS, or sham rTMS for each time point. In addition, a baseline control group receiving no rTMS at all was studied (17 groups in total). The red figure-of-eight symbol on top of the isolated rat brain shown in the bottom figure indicates the center position and orientation of the coil. Note: the coil is much bigger than shown in the drawing and windings in the center at the contact point of both coils cover the entire brain.

\section{Materials and Methods}

Animals and anesthesia. In case of acute experiments, adult Dark Agouti rats (male, 250-300 g) were anesthetized by intraperitoneal injection of urethane (Sigma, $1.5 \mathrm{~g} \cdot \mathrm{kg}^{-1}$ body weight), and stayed anesthetized during rTMS applications and electrophysiological recordings to minimize stress-related effects (Michaluk et al., 2001). Artificial somesthetic sensations and corresponding arousal effects were prevented by additional anesthesia and paralysis of skin and muscles of the head and neck by the aid of local lidocaine hydrochloride injections (Xylocain 4\%, AstraZeneca). To avoid interferences of visual activity with the rTMS-induced effects, a light-dense plastic foil covered the rat's eyes. Body temperature was continuously monitored and maintained between 37 and $37.5^{\circ} \mathrm{C}$ with a feedback-controlled heating pad. Naive control rats receiving no rTMS, were deeply anesthetized with Pentobarbital-Sodium (300 $\mathrm{mg} \cdot \mathrm{kg}^{-1}$ body weight, i.p., Narcoren, Rhone Merieux $\mathrm{GmbH}$ ) and quickly perfused to prevent fast changes in protein expression. Animals surviving for up to $7 \mathrm{~d}$ after rTMS were lightly anesthetized/sedated with medetomidinhydrochloride (Dormitor, Pfizer/Orion Pharma, 0.3 $\mathrm{mg} \cdot \mathrm{kg}^{-1}$ body weight, i.m.) during rTMS. Recovery from anesthesia was accelerated with atipamezolhydrochloride (Antisedan, Pfizer/Orion Pharma, $1.5 \mathrm{mg} \cdot \mathrm{kg}^{-1}$ body weight, i.m.). Only in case of EEG and local field potential (LFP) recordings, rats were mechanically fixed using stereotaxic equipment. In the other cases, sheets of cellulose tissue were used to support the head in an elevated position with the nose pointing downward by $\sim 45^{\circ}$, to prevent direct stimulation of parts of the body and stimulation of the retinas. Animal experiments were performed with the permission of the government (AZ.50.8735.1 105/7 and 9.93.2.10.32.07.057) and the local animal welfare committee. All procedures conformed to the guidelines of the animal welfare laws in Germany, UK and the United States.

rTMS protocols. One low-frequency rTMS protocol $(1 \mathrm{~Hz})$ and two high-frequency theta-burst protocols (iTBS and cTBS) were applied using a "MagStim rapid" and a $70 \mathrm{~mm}$ butterfly coil (The MagStim Company Ltd.). These rTMS protocols were chosen to compare-as in previous studies - the effects of low $(1 \mathrm{~Hz})$ - and high-frequency stimulation (TBS), and the effects of different train durations (iTBS vs cTBS). The coil was centered $8 \mathrm{~mm}$ above occipital pole of the rat's brain with the handle pointing to the left, thus inducing an electric field of mediolateral orientation to primarily stimulate the axons of the corpus callosum (further details following). For standard $1 \mathrm{~Hz}$ rTMS, three trains of $20 \mathrm{~min}$ duration were applied within $70 \mathrm{~min}$ (3600 stimuli in total). In case of iTBS, 20 trains of ten $50 \mathrm{~Hz}$ bursts ( 3 pulses) repeated at $5 \mathrm{~Hz}$ (Huang et al., 2005) were applied at 10 second intervals (600 stimuli). This pattern was repeated five times at 15 min intervals (3000 stimuli in total within 63 min). For cTBS, a single $40 \mathrm{~s}$ train of $50 \mathrm{~Hz}$ bursts repeated at $5 \mathrm{~Hz}$ (also 600 stimuli) (Huang et al., 2005) was applied five times at 15 min intervals (3000 stimuli in total within $61 \mathrm{~min}$ ). Stimulus strength was in a range of $25-33 \%$ of maximal device output, with $1 \mathrm{~Hz}$ rTMS in the upper range (30-33\%) and TBS in the lower one (25-29\%). Stimulus strength was adjusted to be just subthreshold for evoking visible activity in neck and limb muscles. This range of stimulation strength had previously been found to be perithreshold for modulating spiking activity in cat visual cortex (Moliadze et al., 2003) and induced specific changes in immediate early gene expression in a previous study in rats (Aydin-Abidin et al., 2008). The distance between coil and rat cortex was increased to $8 \mathrm{~cm}$ in case of sham stimulation.

At a distance of $10 \mathrm{~mm}$ from coil surface an inducing current of $30 \%$ of maximal output produces a magnetic field strength of $\sim 0.5$ tesla and the induced electric field gradient would be $\sim 130 \mathrm{~V} / \mathrm{m}$ in the human brain. In the in vitro studies of Maccabee et al. (1993) and Rotem and Moses (2006), 20\% of maximal stimulator output was sufficient to activate the axons of a nerve preparation with termination or curvature within the magnetic field, corresponding to a measured electric field strength of $\sim 100 \mathrm{~V} / \mathrm{m}$ at $8 \mathrm{~mm}$ distance from coil and $130 \mathrm{~V} / \mathrm{m}$ at a distance of $5 \mathrm{~mm}$. In a sphere model, Weissman et al. (1992) demonstrated that the electric field induced in the small brain of a rat is only $37 \%$ of the strength induced in a sphere of the size of a human brain. Accordingly, we induced an electric field of $37-50 \mathrm{~V} / \mathrm{m}$ at the level of the subcortical white matter including the corpus callosum. This field strength may be sufficiently strong enough to stimulate superficial cortical areas directly via activation of the long and bent axons of the corpus callosum, but may be too weak to cause direct stimulation of remote brain areas. In a previous study, we found almost no changes in immediate early gene expression in the hippocampus following rTMS, while other subcortical brain regions related to the limbic and arousal systems showed substantial changes in the expression of these markers also in case of sham stimulation (AydinAbidin et al., 2008). These findings are indications of a more general brain activation due to arousal rather than of a direct stimulation of these brain structures by the magnetic field. Using up to $30 \%$ stimulation strength there was no evidence of seizure activity in anesthetized animals.

Electrophysiology. To evaluate the direct effects of rTMS on electrical cortical activity, we recorded EEG activity, MUA, and sensory evoked responses. The EEG is useful to analyze oscillatory cortical activity and changes in the general state of brain activation, MUA allows measurement of the rate and pattern of spontaneous neuronal activity, and sensory evoked responses are useful to investigate the state of cortical information processing. Stable EEG recordings from rat frontal cortex regions were achieved by fixing a chlorided silver-ball electrode $(1 \mathrm{~mm})$ epidurally at a position two millimeters anterior to bregma and onemillimeter lateral to the sagittal plane according to the coordinates of rat brain atlas of Paxinos and Watson (1986) using dental cement. A reference electrode (chlorided silver wire) was placed below the skin of the neck. EEG signals were bandpass filtered at $1-200 \mathrm{~Hz}$ and amplified $2000 \times$. For recordings of MUA and SEPs, a varnished tungsten wire $(\sim 1$ $\mathrm{M} \Omega$ and 1-2 $\mu \mathrm{m}$ tip size, FHC) was lowered to layer IV of the somato- 
sensory cortex $(\sim 700 \mu \mathrm{m}$ depth $)$ at the representation of a toe of the contralateral hindlimb (usually the third or fourth toe). SEPs were bandpassed at $10-3000 \mathrm{~Hz}$ with a gain of $2000 \times$, while MUA was bandpassed between 300 and $3000 \mathrm{~Hz}$ and sampled with a gain of 10,000×. All data were sampled and processed using the "CED Power 1401" interface and the "Spike2" software (both Cambridge Electronic Devices). All wires used for EEG and LFP recordings were positioned at right angles with regard to the electric field induced by the coil to reduce artifact size. The tungsten wire penetrated the center of the figure-of-eight coil vertically through a tubing (special coil design by The MagStim Company Ltd.) to enable recordings of neuronal activity within the center of the magnetically induced electric field.

Electrical stimulation of one toe of the rat hindlimb contralateral to the cortical recording site was achieved by placing one stainless steel needle just below the epidermis of the tip of the toe (anodal electrode) and a second at the proximal base of the toe (cathode). Either single or triple current pulses spaced by $35 \mathrm{~ms}$ intervals were applied with $0.8 \mathrm{~mA}$ current strength and $0.1 \mathrm{~ms}$ pulse duration. Stimuli were repeated 30 times at intervals of two seconds to achieve smooth averaged SEP waveforms. Within layer IV, SEPs were usually dominated by one early negative wave peaking at $\sim 10-15$ ms poststimulus. SEP amplitude was automatically determined by the absolute mathematical difference between the negative peak value and a preceding positive peak value. In case of triple stimulation, we applied the same analysis also to the second and third responses. To determine short-latency afferent inhibition [paired-pulse afferent inhibition (PPAI), used to measure strength of cortically evoked inhibition in human studies (Ragert et al., 2004)], we calculated the ratio of the second to the first SEP amplitude.

We used urethane for the acute electrophysiological experiments because it little affects GABAergic transmission when it is applied at a low dose (Minchin, 1981; Griffiths and Norman, 1993; Hara and Harris, 2002). Moreover, it does not affect the natural sleep rhythm (Clement et al., 2008), indicating that the balance of excitatory and inhibitory system is not much disturbed by urethane. Rats of the subchronic groups $(1,3$, or $7 \mathrm{~d}$ ) were transiently sedated with Dormitor which is an agonist of $\alpha_{2}$-adrenoceptors, and does not act on GABA and benzodiazepine binding sites (Sinclair, 2003).

Immunohistochemistry. To determine the spatial distribution and the amount of expression of distinct functional proteins by cortical interneurons, we used immunohistochemical and immunoblotting methods (Western blot, see Materials and Methods, Western blotting), respectively. In case of acute rTMS experiments, rats were transcardially perfused with $0.9 \% \mathrm{NaCl}$ followed by $4 \%$ paraformaldehyde in $0.1 \mathrm{M}$ phosphate buffer, $\mathrm{pH} 7.4, \sim 2 \mathrm{~h}$ after onset of rTMS with anesthesia deepened by injection of Pentobarbital-Sodium $\left(300 \mathrm{mg} \cdot \mathrm{kg}^{-1}\right.$ body weight, i.p.). Rats surviving up to $7 \mathrm{~d}$ after rTMS were perfused in the same way using pentobarbital anesthesia. After postfixation, brains were cryoprotected using PBS containing 30\% sucrose. Serial sections of 30 $\mu \mathrm{m}$ were cut coronally and each tenth section was stained with cresyl violet (a Nissl stain) for cytoarchitectural control. Consecutive serial sections adjacent to Nissl-stained sections from visual $(-4.3 \mathrm{~mm}$ to bregma according to Paxinos and Watson, 1986), somatosensory $(-1.8$ $\mathrm{mm})$, motor $(+1.2 \mathrm{~mm})$ and frontal $(+3.7 \mathrm{~mm})$ cortex were incubated overnight at room temperature with one of the following antibodies: mouse-anti-NeuN (Neuron-specific Nuclear antigen, 1:100, Millipore), mouse-anti-PV (clone 235, 1:1000, Swant), rabbit-anti-PV (1:1000, Swant), mouse-anti-CB (clone 300, 1:250, Swant) or polyclonal rabbitanti-CR (1:1000, Swant). Next, sections were processed with appropriate secondary antibodies (Vectastain, Vector Laboratories, 1:200 in PBS, $1.5 \mathrm{~h}$, room temperature) followed by a standard avidinbiotinylated peroxidase complex (ABC) kit (1:500, Vectastain, $1.5 \mathrm{~h}$, room temperature). All markers were visualized with $3,3^{\prime}$-diaminobenzidine as chromogen. Finally, sections were rinsed in buffer, dehydrated, cleared in xylene and coverslipped with Depex (Serva). Negative controls were performed with another adjacent section, which was reacted in the same ways as described above, but omitting the primary antibodies.

Quantitative analysis of immunolabeled neurons. Quantitative analysis of immunolabeled neurons was performed manually and automatically (Benali et al., 2003) using a Leitz Wetzlar Dialux 20 microscope (Leica) equipped with a color video camera (CCD KH 609, Leica). Two to three stained coronal cryosections per cortical area [region of interest (ROI)] were measured with a calibrated microscope stage (Leica DMRB), and equipped with the Neurolucida system (MicroBrightField). Neuronal tissue tends to shrink when fixed with paraformaldehyde, and mounting of brain slices leads to flattening. Thus, the absolute values presented might be distorted by the experimental procedure, but for checking this, we made measurements on shrinkage of the tissue in different sections. The variation between the sections and between the groups was $\sim \pm 3$ $\mu \mathrm{m}$. We could not find significant differences $(p>0.5)$ in the $z$-axis between the different groups, so that the shrinkage factors were more or less similar. We only counted clearly labeled somata, without regard to the labeling or visibility of proximal dendrites. Using a magnification of $100-400 \times$, cells were counted only if a continuous cytoplasmic or membranous ring of immunostaining was visible. Cell profile counting and quantitative analysis were performed by two independent raters (J.T., A.B.). Both were blind to the rTMS protocol when counting. A third person (A.M) was consulted if the difference in interrater reliability between J.T. and A.B. (range $95.5-100 \%$ ) was $<95 \%$.

As such, this way of counting neurons on the basis of soma profiles should be viewed as a lower bound of the true size of the population of neurons in the ROI. Counts were made from montages of light micrographs using Photoshop CS (Adobe Systems). Columns (ROI) extended from the pial surface to the white matter and had a mediolateral width of $730 \mu \mathrm{m}$, measured in layer IV.

Double fluorescence labeling of parvalbumin and $K v 3.1 \mathrm{~b}$ or perineuronal nets. Due to a complete loss of PV immunoreactivity in many neurons, it was difficult to determine whether these neurons died or specifically lost only the PV phenotype. Therefore, we performed also double-labeling studies of the expression of PV and components of the extracellular neuronal net specific to PV-expressing neurons, which can be detected via the Wisteria floribunda agglutinin (WFA) (Härtig et al., 1992). Additionally, we tested the expression of Kv3.1b, a potassium channel subunit highly expressed in PV-positive neurons (Weiser et al., 1995). Freefloating sections were blocked for $1 \mathrm{~h}$ with $10 \%$ normal goat serum (NGS) in PBS with $0.2 \%$ Triton. Subsequently, sections were incubated with a mixture of mouse-anti-PV (clone 235, 1:1000, Swant) and rabbitanti-Kv3.1b (1:1000, gift from W. Härtig, Leipzig, Germany) or biotinylated WFA (1:1000, Sigma) in $1 \%$ NGS at $4^{\circ} \mathrm{C}$ overnight. After three rinses with PBS the sections were processed for $1 \mathrm{~h}$ with a second mixture of carbocyanine 2 (Cy2)-conjugated goat-anti-mouse IgG (1:200, Dianova) and Cy3-tagged goat-anti-rabbit Fab fragments (1:200, Dianova) in PBS containing $1 \%$ NGS in case of the PV/Kv3.1b combination. For combined labeling of PV and WFA, sections were incubated for $2 \mathrm{~h}$ at $4^{\circ} \mathrm{C}$ with Cy5-conjugated streptavidin (1:3500, Dianova) in 1\% goat serum. Following three rinses with PBS, sections were processed for $1 \mathrm{~h}$ with Cy2-coupled goat-anti-mouse IgG (1:200, Dianova). After further rinsing, sections were mounted on fluorescence-free slides, air-dried and coverslipped with Depex (Serva). Slides were routinely examined with a laser scanning microscope (Leica).

Terminal deoxynucleotidyl transferase-mediated dUTP nick-end labeling staining. To check for apoptotic cell loss, we stained sections from frontal and visual cortex (compared with liver and testis as positive controls) with the in situ terminal deoxynucleotidyl transferase-mediated dUTP nick-end labeling (TUNEL) 2, 24, and $72 \mathrm{~h}$ post-TMS application. Following supplier's recommendations (Millipore), we used an ApopTag Peroxidase In Situ Apoptosis Detection Kit (S7100-KIT, Millipore) to label apoptotic nuclei. Thereafter, sections were counterstained with methyl green ( $0.5 \%$ in $0.1 \mathrm{~m}$ sodium acetate, $\mathrm{pH} 4.0)$ and mounted on slides, air-dried and coverslipped with Depex (Serva).

Immunelectron microscopy. Electron microscopic sections were analyzed to compare the cellular integrity of PV neurons showing either low or high expression of the PV protein and to detect neuronal damage. A detailed description of the method has been published previously (Petrasch-Parwez et al., 2004, 2007). Sections for immunohistochemistry were reduced in $1 \% \mathrm{NaBH}_{4}$ in $\mathrm{PBS}$ for $30 \mathrm{~min}$ and incubated freely floating for $30 \mathrm{~min}$ in PBS containing 10\% normal NGS. This was followed by incubating the sections for $72 \mathrm{~h}$ at $4^{\circ} \mathrm{C}$ with a monoclonal anti-PV (clone 235, 1:1000, Swant) and a polyclonal anti-WFA (1:1000, Sigma) as primary antibodies, diluted in the previous solution. Sections 
$\mathrm{a}_{1}$
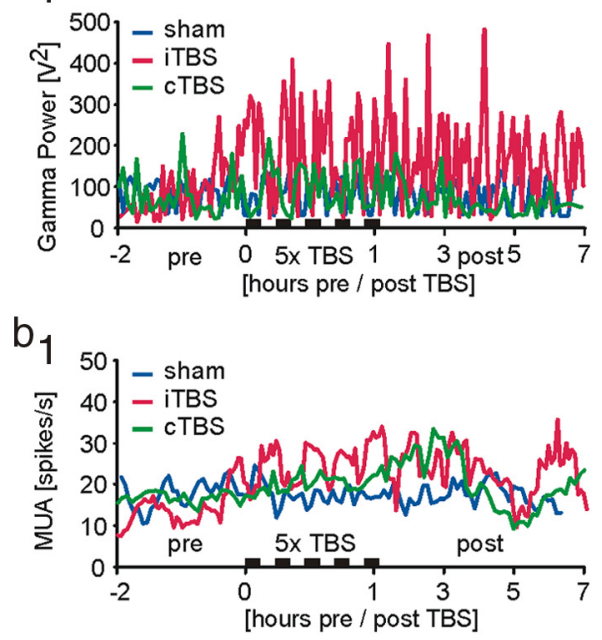

$\mathrm{a}_{2}$

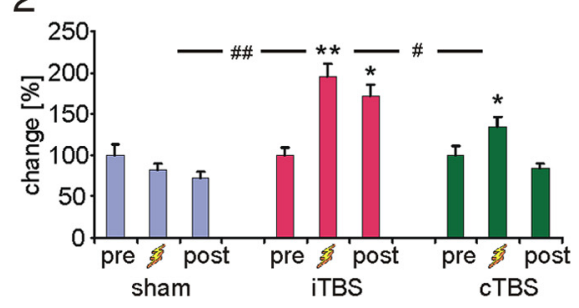

$\mathrm{b}_{2}$

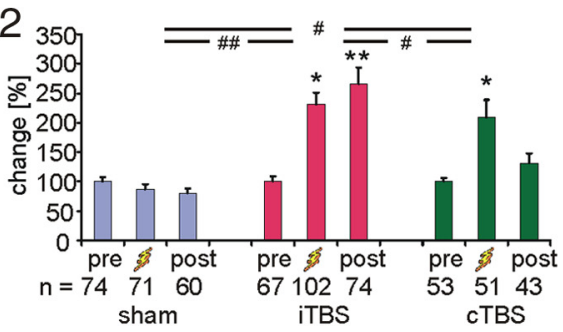

C
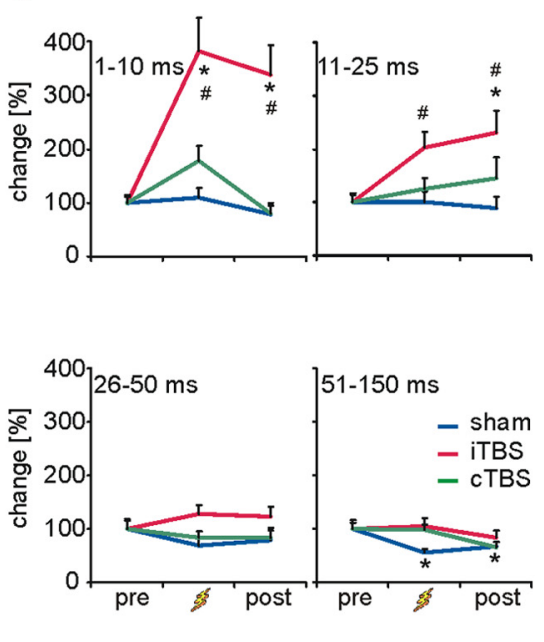

Figure 2. rTMS-induced changes in spontaneous MUA and EEG gamma-power. $\boldsymbol{a}_{1}$, Time course of changes in the gamma-power of the EEG for the two groups of experimental animals receiving either iTBS or cTBS ( 5 times at 15 min intervals) and a control group receiving sham-TBS (4 rats per group). Individual measurements were temporally aligned to the onset of the first TBS application (time $=0$ ). $\boldsymbol{a}_{2}$, Mean and SEM of gamma-power during the three measurement episodes [pre, during (zigzag symbol), post] and for the three experimental groups. For each group, data are normalized, dividing them by the mean of the data points of the pre-TBS condition. $\boldsymbol{b}_{\mathbf{1}}, \boldsymbol{b}_{\mathbf{2}}$, Time course and statistics for mean spontaneous MUA rate. Different from gamma-power, temporal change in MUA rate $\left(\boldsymbol{b}_{\boldsymbol{1}}\right)$ is smoothed by a sliding mean build by averaging 7 consecutive data points. $\boldsymbol{c}$, Relative changes in the interspike interval distribution within ranges of $1-10,11-25,26-50$, and 50-150 ms, corresponding to $100 \mathrm{~Hz}$ and higher, $40-100 \mathrm{~Hz}, 20-40 \mathrm{~Hz}$, and $<20 \mathrm{~Hz}$, respectively. ${ }^{*} p<0.05$, ${ }^{* *} p<0.01$ (Tukey's post hoc test), significant difference from pre condition within each group; ${ }^{\#} p<0.05, " \# p<0.01$ (ANOVA), significant differences between groups.

were washed in PBS, preincubated with $0.1 \%$ bovine serum albumin (BSA) in PBS for $1 \mathrm{~h}$, and then incubated with appropriate secondary antibodies (Vector Laboratories) for $24 \mathrm{~h}$ at $4^{\circ} \mathrm{C}$. After washing and blocking, sections were further incubated for $4 \mathrm{~h}$ with $\mathrm{ABC}$ (Vector Laboratories) in $0.1 \%$ BSA. Peroxidase activity was visualized with $3,3^{\prime}$ diaminobenzidine. Afterward, these sections were photodocumented for later detection of the reaction product, and postfixed with $2 \%$ osmium tetroxide in PBS for $30 \mathrm{~min}$, dehydrated, and finally flat-embedded in Araldite (Serva). Alternating semithin $(0.8 \mu \mathrm{m})$ and ultrathin $(100 \mathrm{~nm})$ sections were cut with an Ultracut UCT microtome (Leica). Every second semithin section was counterstained with $1 \%$ toluidine blue, $\mathrm{pH} 8.9$, and adjacent ultrathin sections were contrasted with $5 \%$ aqueous uranyl acetate for $5 \mathrm{~min}$, followed by a $5 \mathrm{~min}$ staining step with lead citrate $(\mathrm{pH}$ 12). Light microscopic pictures were taken with a DP 71 camera (Olympus) mounted on an Olympus light microscope $\mathrm{BH}-2$, and documented by the computer-assisted analysis system (Soft Imaging System $\mathrm{GmbH}$ ). Ultrathin sections were viewed in a Philips EM 420 electron microscope, documented by the digital system DITABIS (Digital Biomedical Imaging Systems).

Western blotting. Samples from visual and frontal cortex were prepared, and equal amounts of protein from controls and iTBS-treated animals were separated by SDS-PAGE and finally processed for conventional immunoblotting, using antibodies directed against PV (rabbit anti-PV, Swant) and $\beta$-tubulin (Sigma-Aldrich), respectively. For reference, tissue probes from liver (lacking PV) and muscle (containing high amounts of PV) were included in the analysis. Changes in the amount of PV protein were corrected for the amount of $\beta$-tubulin labeling (set to $100 \%$ in each case). Subsequent immunodetection was performed with horseradish peroxidase-coupled anti-rabbit or anti-mouse IgGs followed by the use of an enhanced chemoluminescence system (GE Healthcare). Optical densities of protein labeled bands were quantified using Leica QWin software package.

Reverse transcriptase-PCR. Reverse transcriptase-PCR (RT-PCR) was performed to determine the amount of mRNA coding for PV in comparison with the amount of PV protein itself as determined by Western blot. Total RNA of cold Ringer-perfused fresh frozen tissues of visual, somatosensory, motor and frontal cortices, as well as other specimens, was extracted using the TRIzol protocol. Equal amounts of photometrically measured RNA were transcribed into cDNA. Aliquots were used in the duplex PCR with primers designed for PV and the housekeeping gene S14 that was taken as reference, whereas a 100 base pair DNA ladder was used as reference scale. After adequate number of amplification cycles, the PCR products were analyzed by electrophoresis on a $1.5 \%$ agarose gel containing ethidium bromide for visualization. Digital photos were taken with the Biocapture System (LTF Labortechnik, Wasserburg, Germany) at a setting avoiding saturation levels for analysis of the labeling intensity.

Statistics. Results are presented as means \pm SEM. Statistical significance $(p<0.05)$ was tested with ANOVA and post hoc Tukey test in case of immunohistochemical and electrophysiological data and with unpaired Wilcoxon test in case of Western blot, using a statistical software package (SPSS, Version 17.0.0).

\section{Results}

Effects of rTMS on EEG activity, spontaneous MUA, and SEPs The electrophysiological experiments revealed that iTBS and cTBS (4 animals each) had different effects on EEG activity, spontaneous MUA and sensory evoked responses. Compared with control (sham, 4 animals) experiments, iTBS significantly increased the gamma power of the EEG not only during the $1 \mathrm{~h}$ episode of five iTBS applications but also for a couple of hours thereafter, while cTBS had no significant late effects on the EEG (Fig. $2 a_{1}, a_{2}$ ). Also the power of the other principal EEG bands (delta, theta, alpha, and beta) increased over time but the difference between verum and sham experiments was not significant (see also supplemental Fig. S1, available at www.jneurosci.org as supplemental material). Only the beta band showed a trend comparable to the changes in the power of the gamma band following iTBS. Similarly, spontaneous MUA firing rate, recorded from layer IV of the rat's somatosensory cortex, strongly increased during iTBS and remained elevated for hours, while cTBS had no lasting effect (Fig. $2 b_{1}, b_{2}$ ). Analysis of the interspike interval distribution of MUA revealed that particularly the number of short spike intervals within the range of 1-25 ms strongly increased (Fig. 2c), indicating not only a rise in spontaneous spiking activity but also a higher correlation or synchronization of spik- 
ing activity when considering population activity (MUA of $\sim 3-4$ units). Increased neuronal population activity characterized by interspike intervals shorter than $25 \mathrm{~ms}$, resembling firing rates above $40 \mathrm{~Hz}$, is largely in accordance with the increase of EEG gamma power as has been suggested also by Allen et al. (2007) when observing an increase in gamma power and a shift of interspike interval distributions to shorter intervals following application of short TMS trains to the visual cortex of anesthetized cats. Since EEG signals predominantly capture pyramidal cell activity and because spike interval distribution of MUA exhibited a Poisson-like pattern (data not shown), MUA may largely resemble pyramidal cell activity. However, a contribution of FS cell activity to enhanced MUA cannot be excluded. Although reduced PV expression following iTBS indicates reduced activation of FS cells in general (see Discussion), repeated somesthetic stimulation may increase activity in a subset of FS cells according to the afferent drive, similarly as we propose for the combination of learning with rTMS (Mix et al., 2010).

SEPs were elicited by electrically stimulating one toe of the rat's hindpaw by a triple-pulse protocol of $35 \mathrm{~ms}$ interpulse interval. Using this protocol, we could not only estimate the resting excitability of the cortical network via the first SEP elicited, but also the change in cortical excitability resulting from inhibition of the second response induced by the first response. This inhibition, also known as the cortical recovery function (Allison, 1962), has been used as a test paradigm of cortical inhibition in human somatosensory cortex, here termed paired-pulse inhibition (Ragert et al., 2004). A similar cortical form of inhibition evoked by stimulation of somatosensory afferents is described for human motor cortex as short-latency afferent inhibition of motorevoked potentials (Tokimura et al., 2000). Here, we use the term PPAI (Funke and Benali, 2009). The amplitude of the third SEP in this series helps us to decide whether the decline of the second response is indeed due to cortical inhibition or a result of transmitter depletion or short-term synaptic depression. The third response amplitude was often larger than that of the second response and the amplitude of the following responses oscillated in a dampened manner (separately obtained data not shown), pointing to active cortical inhibition rather than synaptic decline which would result in a monotonic decrease of SEP amplitudes (Hoshiyama and Kakigi, 2003).

Following both, iTBS and cTBS, the first SEP amplitude increased, while the second response slightly declined after iTBS but clearly increased following cTBS. The increased first, but decreased second response, resulted in a strengthening of PPAI (lowered SEP2/SEP1 ratio, Fig. 3) in case of iTBS. No significant change in PPAI was evident for cTBS, because the relative increase in both response amplitudes was almost identical. Control experiments with sham stimulation were performed to check whether SEP amplitudes may change over time as a matter of changing depth of anesthesia, general physiological condition of the animal (see supplemental Fig. S2, available at www.jneurosci. org as supplemental material, for comparison of EEG status), and as a possible result of repeated sensory stimulation. Especially the steady increase in the amplitude of the first SEP following rTMS could likely be related to response potentiation by repeated stimulation. However, all SEP amplitudes declined during the late part of the control experiments, resulting in a significantly increased first SEP following iTBS and cTBS and strengthened evoked cortical inhibition following iTBS (Fig. 3).

In summary, our electrophysiological data reveal that iTBS and cTBS resulted in a different modulation of cortical activity:
iTBS, but not cTBS, increased spontaneous activity and EEG gamma power, indicating enhanced cortical excitability. Additionally, iTBS increased both, sensory evoked cortical excitation and inhibition, while cTBS raised evoked response amplitudes without signs of altered short-latency afferent inhibition. As we will further demonstrate, and discuss in more detail later on, iTBS and cTBS seem to modulate the activity of different classes of inhibitory cortical interneurons.

\section{Effects of rTMS on cortical protein expression}

Changes in the cortical expression of proteins induced by rTMS were studied early after stimulation (acute; $\sim 2 \mathrm{~h}$ from onset; $6-8$ animals per group) and in part up to a week post-rTMS (subchronic; 1, 3, or $7 \mathrm{~d}$; 3-4 animals per group). Acute changes in the expression of the CaBPs PV, CB, and CR were clearly different following iTBS or cTBS. Compared with sham-treated and naive controls receiving no rTMS, iTBS strongly (40-70\%) reduced the number of PV-positive cells in all cortical areas analyzed without significantly affecting the CB and CR immunoreactivity (Fig. 4; supplemental Fig. S3a, available at www.jneurosci.org as supplemental material). Although cortical layers $2 / 3$ often showed a somewhat stronger depletion of PV + cells and weaker staining of the neuropil for PV compared with the other layers, quantitative analysis of the number of PV + cells revealed no principal differences between layers with regard to the different experimental groups (see supplemental Fig. S3b, available at www.jneurosci. org as supplemental material), indicating that even if rTMS primarily activated the upper cortical layers, also interneurons within the deep layers were affected by the induced activity. Delineation of the cortical layers of the motor cortex was performed according the work of van Brederode et al. (1991). In this, and in the publications of Krieg (1946), Skoglund et al. (1997), and Hiscock et al. (1998), the motor cortex was divided into six layers. Although the rat motor cortex is described as a five-layered cortex similar to the human motor cortex (Donoghue and Wise, 1982; Zilles, 1985; Beaulieu, 1993; Zilles and Wree, 1995), we used the subdivision of van Brederode et al.(1991), because Zilles and Wree (1995) described a higher cell packing density in the lower part of layer 3 of the rat motor cortex, that is comparable to layer IV in the sensory regions.

By contrast, cTBS significantly reduced the number of cells expressing $\mathrm{CB}$ by $34-45 \%$, while the numbers of PV-positive neurons were almost unchanged. The reduction in $\mathrm{CR}$-positive cells following cTBS did not reach statistical significance. For comparison, we also tested the effect of the low-frequency $1 \mathrm{~Hz}$ rTMS protocol on CaBP expression. Similar to cTBS, $1 \mathrm{~Hz}$ rTMS significantly reduced the number of CB-positive cells by $30-37 \%$ but did not affect the number of PV-and CR-expressing neurons (Fig. 4).

Investigation of the subchronic rTMS effects revealed a mild recovery of PV immunoreactivity after $1 \mathrm{~d}$ but the reduction in the number of PV-positive cells induced by iTBS persisted for $\sim 7$ $\mathrm{d}$. The weaker reduction in the number of CB-expressing cells induced by cTBS and $1 \mathrm{~Hz}$ rTMS was less persistent, recovering within $1 \mathrm{~d}$ to almost sham control levels (Fig. 5). The rTMS effects were evident in all four cortical areas examined (frontal, motor, somatosensory and visual; see supplemental Fig. S4, available at www.jneurosci.org as supplemental material). A lasting reduction in protein expression is often a matter of restricted synthesis due to lowered mRNA levels coding for the protein. The early reduction in PV expression following iTBS, however, could more likely be a result of an activity-dependent fast degradation of the protein, rather than a reduced synthesis. To check this, Western 

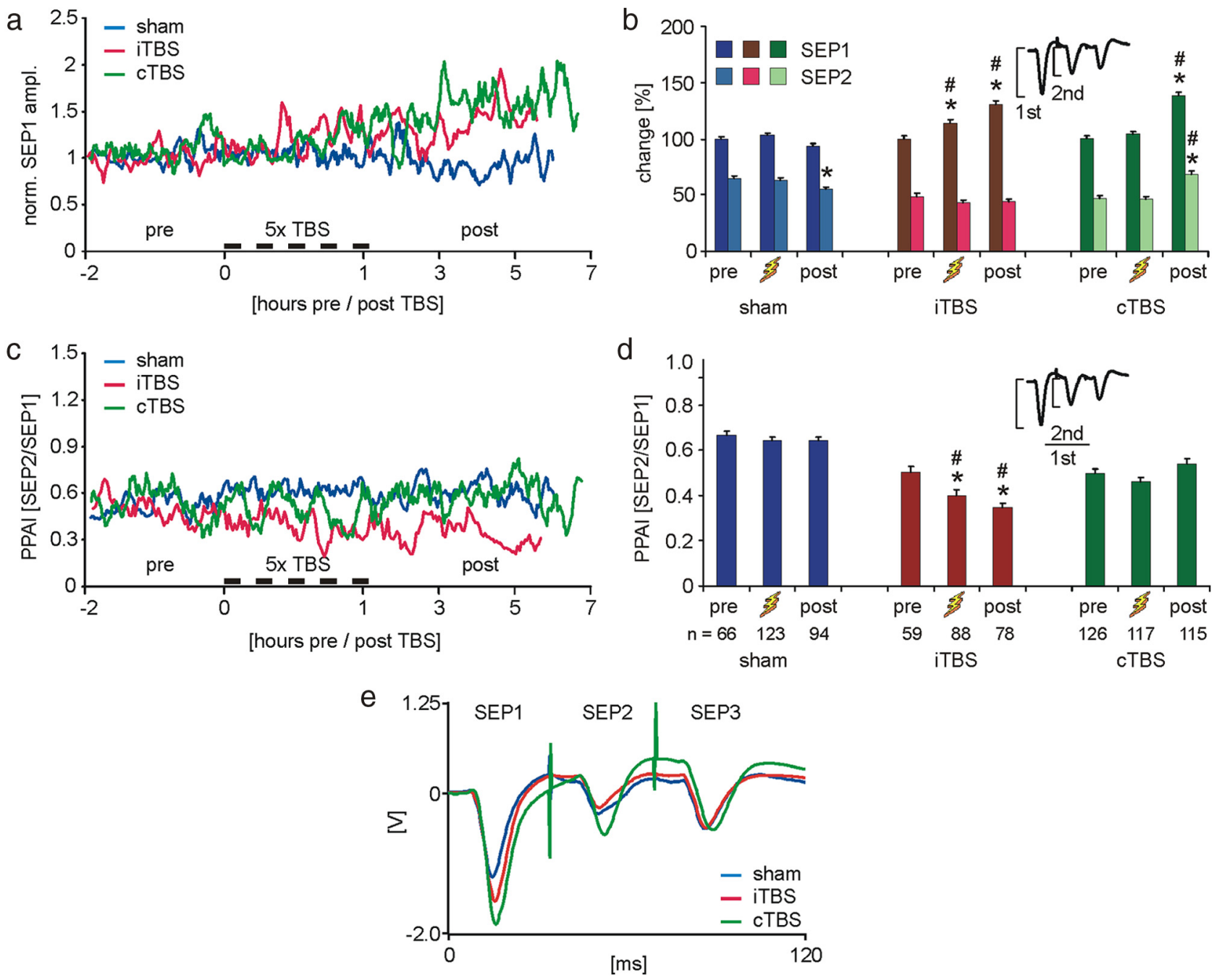

Figure 3. rTMS effects on evoked sensory activity. $\boldsymbol{a}$, Time course of changes in the amplitude of the first SEP (SEP1, electrical stimulation) in a series of three subsequent stimulations. For each group, data are normalized, dividing them by the mean of the data points of the pre-TBS condition. For details on time axis, see legend of Figure 2. $\boldsymbol{b}$, Mean amplitudes and SEM for the first (SEP1) and second (SEP2) evoked response normalized to the pre-TBS conditions. $c$, Temporal change of the PPAI calculated as the ratio of second to first response (SEP2/SEP1) for the three experimental groups. $\boldsymbol{d}$, Means and SEM of PPAI. ${ }^{*} p<0.05$ (Tukey's post hoc test) significant difference from pre condition within each group; ${ }^{\#} p<0.05$ (AN0VA/Tukey), significant differences of same condition between groups. $\boldsymbol{e}$, Averaged SEP traces for post condition of the three experimental groups (not normalized).

Blotting and RT-PCR were performed to quantify the amount of cortical PV protein and mRNA, respectively, early after iTBS $(\sim 2$ $\mathrm{h}$ from onset). As shown in Figure 6, we found no quantitative difference in the cortical amount of the PCR-amplicon, resembling the mRNA coding for PV, between iTBS-treated and control animals. The total amount of PV protein, however, was reduced by $\sim 30 \%$ following iTBS (Fig. 6 ), indicating that iTBS had initiated a fast activity-dependent degradation process for $\mathrm{PV}$, most likely via the proteasome system. In a previous study, we could already show that iTBS also increased the cortical expression of zif268 (Aydin-Abidin et al., 2008), an immediate early gene product which is increased along with long-term synaptic potentiation, and is supposed to increase the proteasome activity (Baumgärtel et al., 2009).

Quantification of protein expression by immunohistochemistry is limited by factors possibly changing immunoreactivity in situ. In case of the calcium-binding proteins $\mathrm{PV}, \mathrm{CB}$ and $\mathrm{CR}$, immunoreactivity was shown to be modulated by the amount of calcium bound to the protein (Winsky and Kuźnicki, 1996). The quantitative analysis of the cortical expression of PV using Western Blotting, however, is independent of the calcium load of the protein due to denaturation of the proteins. Western Blotting resulted in a somewhat less reduction in PV $(\sim 30 \%)$ than immunohistochemistry $(40-70 \%)$ but quantification of PV amount reached a statistically significant level. In addition, we performed immunohistochemistry using two different primary antibodies against PV, a monoclonal mouse anti-PV (clone 235) and a polyclonal rabbit anti-PV, both resulting in very similar staining. It is rather unlikely that both antibodies are affected in the same way by the calcium-dependent change in immunoreactivity of PV. To exclude that formalin-fixation masked the antibody-binding epitope of parvalbumin or calbindin, antigen retrieval (Weiler and Benali, 2005) was performed before immunohistochemical staining. Staining after antigen retrieval showed the same decrease in PV and CB than found after the regular immunoreaction (data not shown).

The observed drastic decline in PV immunoreactivity, with an entire loss of PV phenotype in many neurons, with simultaneous normal PV expression in other cells, raises the question, whether apoptotic cell loss might be involved. To test this hypothesis, the cortical tissue of iTBS- and cTBS-treated rats was further processed for a TUNEL reaction and an electron-microscopic anal- 


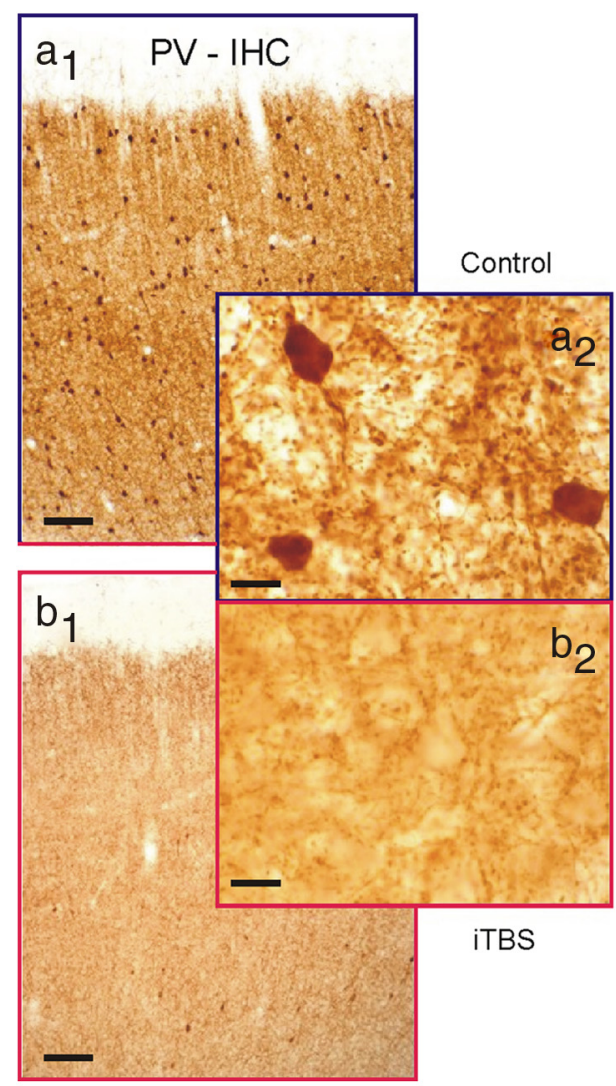

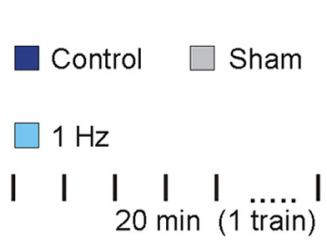

$\square$ iTBS IIIIIIIIII I. IIIIIIIIIII $2 \mathrm{~s} / 8 \mathrm{~s}$ (20 trains)

cTBS $50 \mathrm{~Hz}$ bursts IIIIIIIIIIIIIIIIIIII ......IIIII $40 \mathrm{~s}$ (1 train)

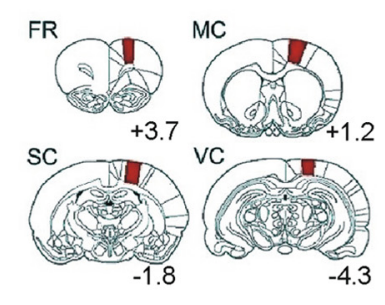

Regions Of Interest (ROI): FR frontal, MC - motor, SC somatosensory, VC - visual cortex
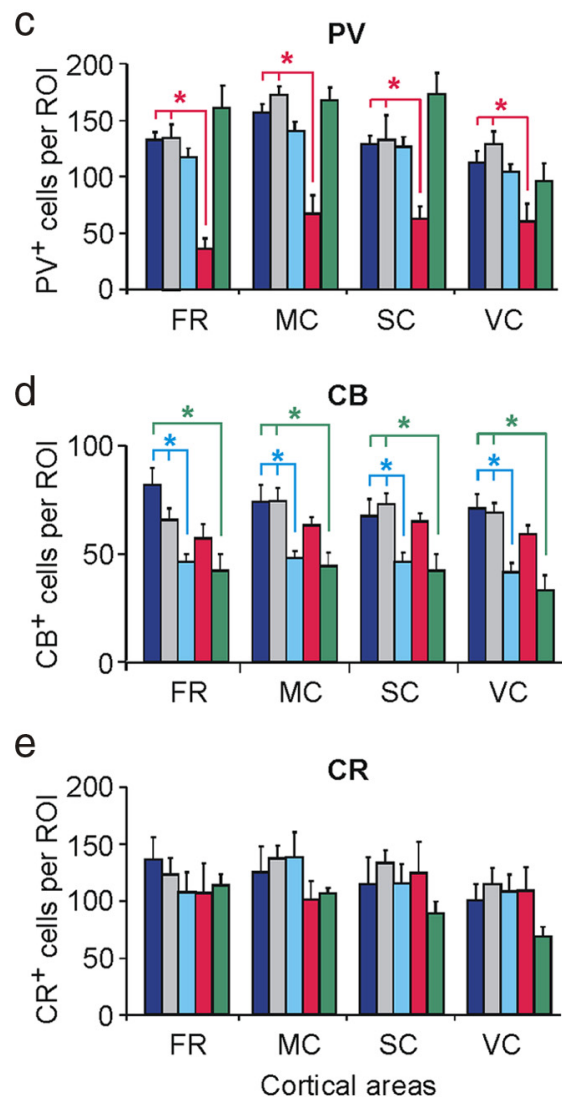

Figure 4. Acute changes in CaBP expression following rTMS. PV expression was strongly reduced $\sim 2 \mathrm{~h}$ after verum iTBS, while CB expression was reduced following cTBS and $1 \mathrm{~Hz}$ rTMS. $\boldsymbol{a}_{1}, \boldsymbol{a}_{2}$, Coronal sections through the frontal cortex of a control rat showing basal expression of PV. $\boldsymbol{b}_{1}, \boldsymbol{b}_{2}$, Same cortical region in a rat treated with iTBS. DAB staining. Scale bar: $\left(\boldsymbol{a}_{1}, \boldsymbol{b}_{1}\right), 100 \mu \mathrm{m} ;\left(\boldsymbol{a}_{2}, \boldsymbol{b}_{2}\right)$, $10 \mu \mathrm{m} . \mathbf{c}-\boldsymbol{e}$, Statistics (means and SEM) of the number of cells expressing PV, CB, and CR in different cortical regions (ROI) (see legend inset) for a baseline control group, a sham-rTMS group, and groups treated with either $1 \mathrm{~Hz}$ rTMS, or iTBS or cTBS ( $n=6-8$ in each group). ${ }^{*} p<0.05$ (Tukey's post hoc test). Inset legend in the middle panel shows the rTMS protocols used (top) and ROls analyzed for stained neurons (bottom). Areas filled in red in the drawings of rat brain frontal sections correspond to Rol. Related numbers indicate anterior $(+)$ to posterior $(-)$ level relative to bregma in millimeters according to Paxinos and Watson (1986). See supplemental Figure S3, available at www.jneurosci.org as supplemental material, for further details.

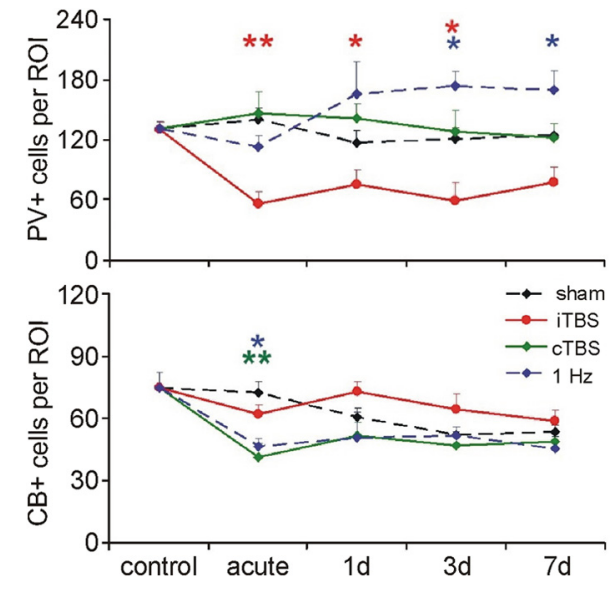

Figure 5. Time course of rTMS-induced changes in PV and CB expression. Acute $(2 \mathrm{~h})$ and subchronic (1-7 d) changes in the number of the cortical cells expressing PV (top) or CB (bottom) following iTBS, cTBS, 1 Hz rTMS and sham stimulation. ${ }^{*} p<0.05,{ }^{* *} p<0.01$ tested with ANOVA (factors: time and experimental condition) and post hoc Tukey test. Each data point represents the mean of $3-4$ animals and averaged data of all ROls (see supplemental Fig. S4, available at www.jneurosci.org as supplemental material, for data of individual ROls).

ysis. In addition, sections were subjected to double fluorescent labeling of PV and either the Kv3.1b subunit of voltagedependent potassium channels or WFA as a marker for a perineuronal net component mainly detected around fast-spiking neurons (Härtig et al., 1992). The TUNEL reaction gave no indications for rTMS-induced apoptotic cell death (see supplemental Fig. S5, available at www.jneurosci.org as supplemental material). Following iTBS but not cTBS, immunofluorescent staining of Kv3.1b, which is mostly expressed in PV-positive interneurons (Weiser et al., 1995) supposed to be the FS neurons also in rat cortex (Kawaguchi and Kubota, 1998), was frequently observed without costaining for PV (Fig. 7a). Furthermore, cells ensheathed by WFA-labeled perineuronal nets were as frequent as in control tissue, but many of these cells missed PV staining following iTBS (Fig. 7b), indicating that these cells were vital despite losing the PV phenotype. Furthermore, the electron microscopic analysis of PV-expressing interneurons did not reveal any morphological differences between neurons that were strongly or very weakly stained for PV, including the extent of the WFAstained perineuronal net around the corresponding interneurons (Fig. 8).

\section{Discussion}

The two theta-burst protocols, iTBS and cTBS-previously shown to modify human cortical excitability in an opposite fashion (Huang et al., 2005)—also affected rat cortical activity and protein expression very differently. Our results indicate that iTBS and cTBS modulate the activity of different inhibitory cortical systems: iTBS primarily targets inhibition of pyramidal cell output activity by PV-expressing interneurons, while cTBS mostly affects the inhibitory activity of the CB-expressing interneurons 
primarily controlling synaptic inputs to pyramidal cells (Kawaguchi and Kubota, 1998; Markram et al., 2004). As will be discussed in more detail below, the former process could be responsible for the enhanced spontaneous MUA and the accompanied increase in EEG gamma power found after iTBS, and would also enable a stronger sensory response evoked from the disinhibited resting cortical activity state. By contrast, disinhibiting the sensory input to pyramids via cTBS may not much affect spontaneous activity but would generally facilitate sensory responses (first and following responses). Quite differently, iTBS led to a stronger inhibition of the second response by the first (PPAI) which was not evident following cTBS. Also this effect can be explained on the basis of reduced PV expression.

The strong loss of PV immunoreactivity signals a reduced activity state of the affected neurons (Bender et al., 2000; Lewis et al., 2005; Tropea et al., 2006; Schwaller, 2009; Sun, 2009). Reduced neuronal activity is likely resulting from a depression of the excitatory inputs. Excitatory synapses at FS inhibitory interneurons largely follow an anti-Hebbian rule of synaptic plasticity (for review, see Kullmann and Lamsa, 2007), showing synaptic LTD after prolonged high-frequency input activity and following repeated application of a spike-time-dependent plasticity stimulation protocol usually inducing LTP in excitatory neurons (Lu et al., 2007). Moreover, brain-derived neurotrophic factor (BDNF) released during high-frequency input activity (Hartmann et al., 2002) promotes synaptic depression at excitatory inputs to PVpositive neurons (Jiang et al., 2004). The repeated and highly synchronous high-frequency activation of excitatory axons induced by iTBS may have the potential to induce LTD of these synapses, resulting in a hypoactivation of the PV cells especially during resting activity states, and a subsequent reduction or loss of PV expression. A single high-frequency input train as induced by cTBS may not be a suitable signal to induce lasting synaptic plasticity. In this respect, it might be worth to consider that the mutual inhibitory connections between GABAergic cells of the FS-type, switch from a hyperpolarizing to a depolarizing action during prolonged high-frequency trains of activity $(20-40 \mathrm{~Hz})$, a matter of the use-dependent shift in the chloride $\left(\mathrm{GABA}_{\mathrm{A}}\right.$-current) equilibrium potential (Lamsa and Taira, 2003). The duration of high-frequency neuronal activation induced by rTMS may determine whether inhibitory interneurons of a certain class inhibit or excite each other. The same variable might influence whether neurons can follow the high rate of stimulation, thereby potentially leading to a different outcome of activity-related plasticity of protein expression and electric activity.

Reduced PV expression resulting from the hypoactivation of FS cells will have further consequences for inhibitory activity which could be fundamental to the enhanced PPAI following iTBS. PV belongs to the class of "slow-type" calcium buffers and usually prevents paired-pulse facilitation of the GABAergic synapse at short spike-intervals (30-100 ms) as shown in the cerebellum (Caillard et al., 2000) and hippocampus (Vreugdenhil et al., 2003). If presynaptic PV content is reduced (Caillard et al., 2000; Rozov et al., 2001), or knocked out (Schwaller et al., 1999), paired-pulse facilitation-a sign of short-term synaptic plasticity-becomes evident at firing a

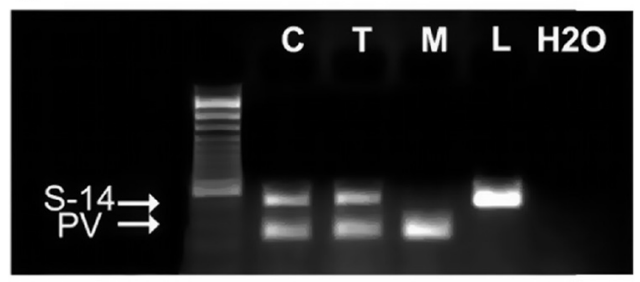

b
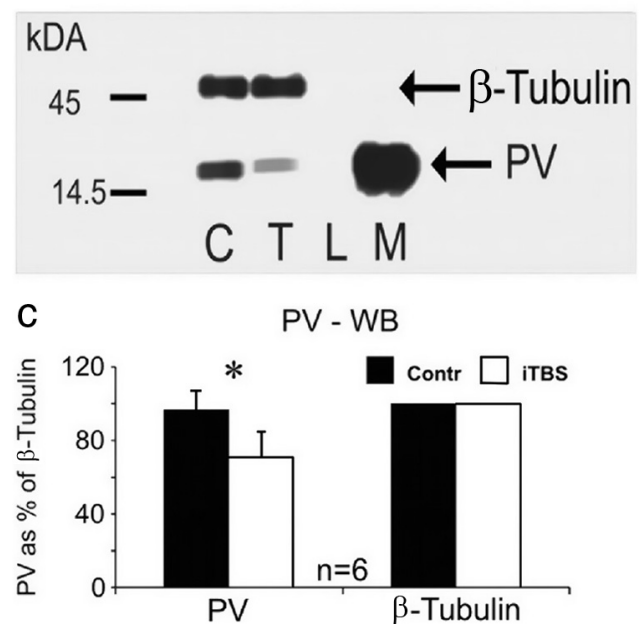

Figure 6. Quantification of PV mRNA and protein. $a$, Quantification of PV-mRNA using RTPCR for tissue probes obtained from the frontal cortex of control rats $(C)$ and iTBS-treated rats (T, acute group), as well as reference tissue probes of muscle (M) and liver (L). No quantitative difference in the amount of the PCR-amplicon resembling PV-mRNA is evident between controls and iTBS-treated animals. Housekeeping gene $\mathrm{S} 14$ was taken for reference and a 100 base pair DNA ladder is shown to the left. A pure water reference $\left(\mathrm{H}_{2} \mathrm{O}\right)$ is added to the right. $\boldsymbol{b}$, Western blot (WB) showing a smaller amount of PV protein in frontal cortex of animals treated with iTBS (T) compared with controls (C). For reference, tissue probes of liver ( $L$, no PV expression) and muscle (M, large amounts of PV) are shown. The expression of the cytoskeletonrelated protein $\beta$-tubulin is not affected. c, WB reveals significantly reduced tissue content of PV in iTBS-rTMS-treated rats compared with controls ( ${ }^{*} p<0.05$, unpaired Wilcoxon test).
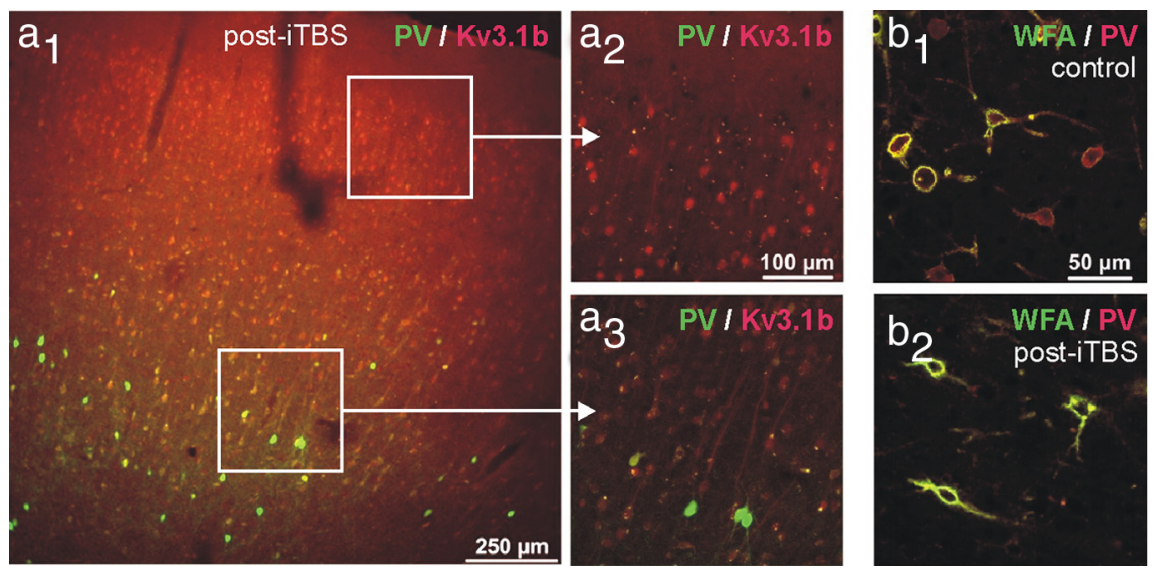

Figure 7. Colabeling of PV with Kv3.1b or WFA. $\boldsymbol{a}_{\mathbf{1}}-\boldsymbol{a}_{\mathbf{3}}$, Coronal sections through the frontal cortex of a rat treated with iTBS. Immunofluorescence labeling of PV (green) and Kv3.1b (red) are combined. Note that supragranular layers almost completely lost PV expression while Kv3.1b is still expressed in many cells. $\boldsymbol{b}_{\mathbf{1}}, \boldsymbol{b}_{\mathbf{2}}$, Following iTBS $\left(\boldsymbol{b}_{2}\right)$, PV cells still exist, as indicated by lectin staining of perineuronal nets (WFA, green), while concomitant immunolabeling (red) reveals the loss of PV phenotype, compared with controls $\left(\boldsymbol{b}_{\boldsymbol{1}}\right)$.
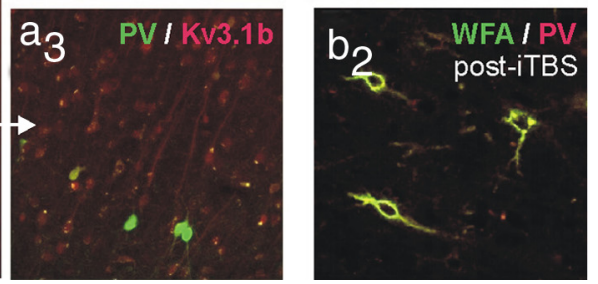

rates above $30 \mathrm{~Hz}$, the dominant firing pattern of FS neurons when tonically activated. Consequently, synaptic inhibition will be strengthened if these interneurons receive strong input, as would be the case during sensory input. Strengthened recurrent 

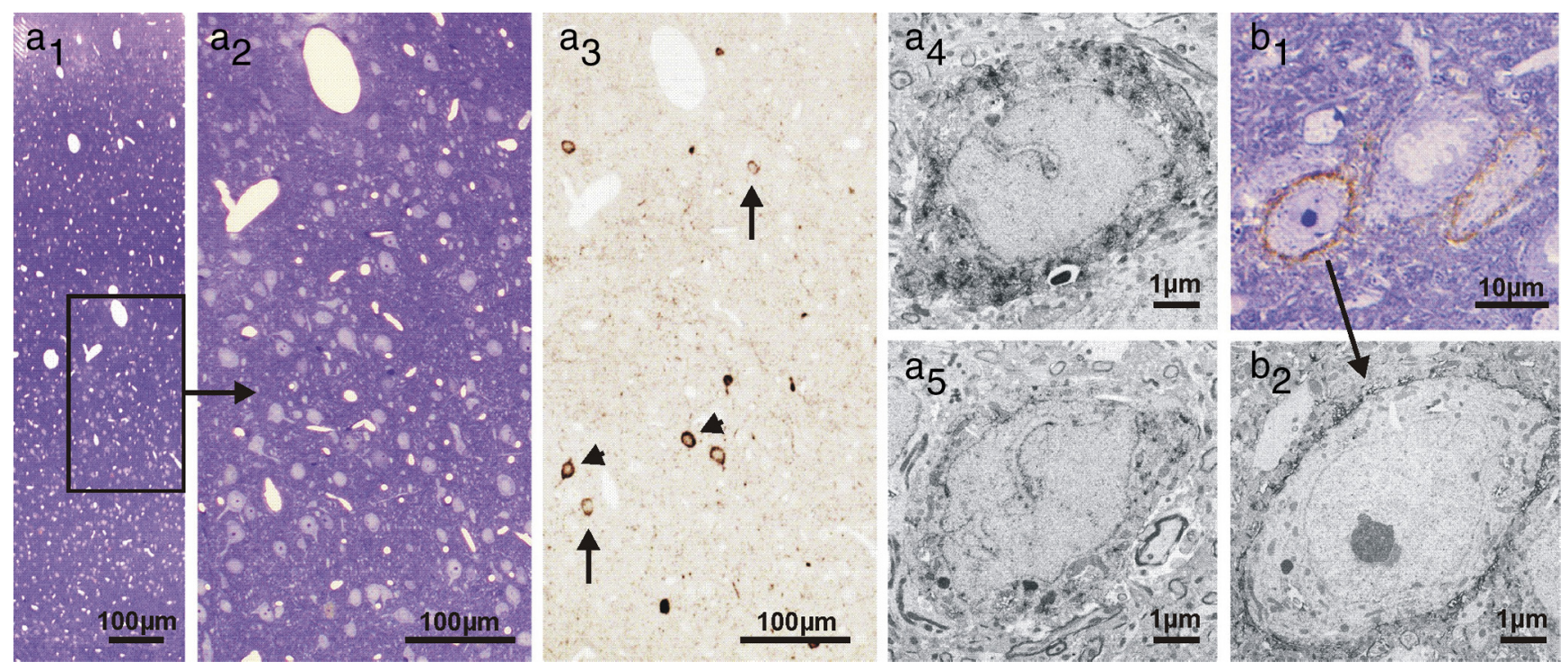

Figure 8. Immunelectron microscopic analysis of PV-positive interneurons and WFA-stained perineuronal nets. PV $\left(\boldsymbol{a}_{1-5}\right)$ and perineuronal net (WFA) $\left(\boldsymbol{b}_{1,2}\right)$ immunoperoxidase labeling of the motor cortex in iTBS-treated rat brain (acute, $2 \mathrm{~h}$ ). Toluidine blue-stained $0.8-\mu \mathrm{m}$-thick semithin section of an area with reduced PV expression shows no signs of cell death $\left(\boldsymbol{a}_{1,2}\right)$. Adjacent semithin section $\left(\boldsymbol{a}_{\mathbf{3}}\right)$ displays single PV-positive neurons with faint (arrows) and strong (arrowheads) immunoreactivity. Electron microscopy exhibits PV-positive interneurons, both with strong $\left(\boldsymbol{a}_{4}\right)$ and weak $\left(\boldsymbol{a}_{\boldsymbol{5}}\right)$ PV immunoreactivity. Integrity of such interneurons is further confirmed by frequently surrounding WFA-positive perineuronal nets detected in toluidine blue-counterstained semithin $\left(\boldsymbol{b}_{1}\right)$ and corresponding ultrathin sections $\left(\boldsymbol{b}_{2}\right)$.

inhibition would then result in a stronger intracortical suppression of sensory activity following at short delays (increase in PPAI). A strengthening of the GABAergic synapses by iTBS is further supported by our recent finding of increased GAD65 expression following iTBS and cTBS (Trippe et al., 2009), which is indicative of enhanced presynaptic GABA-synthesis and release, while the reduction in GAD67 supports the general hypoactivation of inhibitory neurons.

Altered GABAergic synaptic transmission due to a change in the expression of PV and/or the GABA-transporter GAT-1 has been discussed as a possible reason for modified gamma oscillations in schizophrenic patients and animal models of schizophrenia (Lewis et al., 2005; Morris et al., 2005; Pratt et al., 2008; Sakai et al., 2008; Vierling-Claassen et al., 2008). Typically, gamma power then displays less increase during cognitive tasks and, more critically, gamma power does not scale with cognitive demands as found in healthy controls (Cho et al., 2006; Lodge et al., 2009). The loss of either PV, or GAT-1, or both would strengthen and prolong the IPSCs. However, the consequences for oscillatory activity in the gamma range are still a matter of discussion (Lewis et al., 2005). Vreugdenhil et al. (2003) reported a strong increase in the power of kainate-elicited gamma-oscillations in the hippocampus of PV-knock-out mice, supporting our observation of increased cortical gamma and beta power following iTBS-induced decrease in PV. Vierling-Claassen et al. (2008) studied the effect of prolonged IPSCs in an auditory entrainment model of the auditory cortex to simulate altered oscillatory activity related to schizophrenia (Kwon et al., 1999). The model favored an increase in oscillatory activity in the beta range due to prolonged IPSCs, while that in the gamma range was reduced. In schizophrenic patients, usually a decrease in EEG gamma power dominates but many differences between brain regions and animal schizophrenia models exist, showing also increased gammapower following loss of PV (for review, see Roopun et al., 2008). Subnarcotic application of NMDA receptor antagonists mimics or amplifies symptoms of schizophrenia and leads to an increase in ongoing gamma activity in humans (Hong et al., 2010) and rats
(Hakami et al., 2009) and reduces the expression of PV (Pratt et al., 2008). This increase in "gamma noise" (Hakami et al., 2009) may impair the specific generation of oscillatory activity in the gamma range during sensory or cognitive processing. A recent study indeed reported a deficit in event-related inhibition of gamma-oscillation in schizophrenics (Farzan et al., 2010). In summary, these findings indicate that the systems controlling the generation of gamma-oscillations are disturbed in schizophrenia and that fast-spiking PV-expressing interneurons largely contribute to this process.

$\mathrm{CB}$, on the other hand, is a fast-type calcium buffer, limiting transmitter release in response to a single presynaptic action potential but promoting facilitation of synaptic responses with high-frequency spike trains (Caillard et al., 2000; Rozov et al., 2001). This, and the finding that CB is mainly expressed by nonfast-spiking interneurons, providing dendritic rather than perisomatic inhibition (Markram et al., 2004), could explain the different effect on PPAI following cTBS-induced reduction in CB expression. Also CB has been found to be expressed in an activitydependent manner (Tropea et al., 2006; Chaudhury et al., 2008; Mainardi et al., 2009). A reduction in the CB expression and corresponding attenuation of dendritic inhibition could thus explain the general increase in sensory evoked cortical activity.

A couple of rTMS studies in humans also indicate the possible involvement of inhibitory systems in the modulation of cortical excitability. Using magnetic resonance spectroscopy, Stagg et al. (2009) demonstrated an increase in GABA content following cTBS of the human motor cortex. However, with respect to a possibly reduced cortical excitability it has to be considered that extra-synaptic GABA likely inhibits also GABAergic neurons. Huang et al. (2005) reported a decrease in TMS-elicited shortinterval cortical inhibition following cTBS, but an increase after iTBS, which is largely consistent with the enhancement of PPAI we found in rat cortex following iTBS.

A different contribution of cortical subsystems to the effects induced by iTBS and cTBS was also proposed by Di Lazzaro et al. $(2005,2008)$. They concluded that the reduction of the first wave 
of intracortically induced corticospinal activity (I1) following cTBS is caused by suppressed excitatory inputs to cortical output cells, while the enhancement of subsequent activity waves, supposed to be carried by intracortical connections (I2, I3), could be a result of a weakened recurrent inhibition by iTBS. Reduced activity-dependent PV expression in rat cortex following iTBS would support this finding, but compensatory increase in GABAergic synaptic transmission may occur subsequently, possibly reversing the initial effect. Thus, the observed increase in sensory evoked inhibition could be a process that becomes evident somewhat later than usually investigated in human studies (Ragert et al., 2004).

Due to reasons of different spatial patterns of cortical activation by TMS and the likelihood of different cortical activity states, our findings obtained in the anesthetized rat may be not directly applicable to TMS of the human cortex. However, high-frequency and synchronous activation of excitatory axons will also happen with iTBS and cTBS applied to humans and could likely affect the inhibitory cortical systems in a similar way as we found in the rat, a matter worth to be considered for further attempts to modulate human cortical excitability.

\section{References}

Allen EA, Pasley BN, Duong T, Freeman RD (2007) Transcranial magnetic stimulation elicits coupled neural and hemodynamic consequences. Science 317:1918-1921.

Allison T (1962) Recovery functions of somatosensory evoked responses in man. Electroencephalogr Clin Neurophysiol 14:331-343.

Aydin-Abidin S, Trippe J, Funke K, Eysel UT, Benali A (2008) High- and low-frequency repetitive transcranial magnetic stimulation differentially activates c-fos and zif268 protein expression in the rat brain. Exp Brain Res 188:249-261.

Baumgärtel K, Tweedie-Cullen RY, Grossmann J, Gehrig P, LivingstoneZatchej M, Mansuy IM (2009) Changes in the proteome after neuronal zif268 overexpression. J Proteome Res 8:3298-3316.

Beaulieu C (1993) Numerical data on neocortical neurons in adult rat, with special reference to the GABA population. Brain Res 609:284-292.

Benali A, Leefken I, Eysel UT, Weiler E (2003) A computerized image analysis system for quantitative analysis of cells in histological brain sections. J Neurosci Methods 125:33-43.

Bender R, Hoffmann MC, Frotscher M, Nitsch C (2000) Species-specific expression of parvalbumin in the entorhinal cortex of the Mongolian gerbil: dependence on local activity but not extrinsic afferents. Neuroscience 99:423-431.

Blatow M, Rozov A, Katona I, Hormuzdi SG, Meyer AH, Whittington MA, Caputi A, Monyer H (2003) A novel network of multipolar bursting interneurons generates theta frequency oscillations in neocortex. Neuron 38:805-817.

Caillard O, Moreno H, Schwaller B, Llano I, Celio MR, Marty A (2000) Role of the calcium-binding protein parvalbumin in short-term synaptic plasticity. Proc Natl Acad Sci U S A 97:13372-13377.

Cardin JA Carlén M, Meletis K Knoblich U, Zhang F Deisseroth K, Tsai LH Moore CI (2009) Driving fast-spiking cells induces gamma rhythm and controls sensory responses. Nature 459:663-667.

Chaudhury S, Nag TC, Wadhwa S (2008) Calbindin D-28K and parvalbumin expression in embryonic chick hippocampus is enhanced by prenatal auditory stimulation. Brain Res 1191:96-106.

Cho RY, Konecky RO, Carter CS (2006) Impairments in frontal cortical synchrony and cognitive control in schizophrenia. Proc Natl Acad Sci U S A 103:19878-19883.

Clement EA, Richard A, Thwaites M, Ailon J, Peters S, Dickson CT (2008) Cyclic and sleep-like spontaneous alternations of brain state under urethane anaesthesia. PLoS One 3:e2004.

Di Lazzaro V, Pilato F, Saturno E, Oliviero A, Dileone M, Mazzone P, Insola A, Tonali PA, Ranieri F, Huang YZ, Rothwell JC (2005) Theta-burst repetitive transcranial magnetic stimulation suppresses specific excitatory circuits in the human motor cortex. J Physiol 565:945-950.

Di Lazzaro V, Pilato F, Dileone M, Profice P, Oliviero A, Mazzone P, Insola A, Ranieri F, Meglio M, Tonali PA, Rothwell JC (2008) The physiological basis of the effects of intermittent theta burst stimulation of the human motor cortex. J Physiol 586:3871-3879.

Donoghue JP, Wise SP (1982) The motor cortex of the rat: cytoarchitecture and microstimulation mapping. J Comp Neurol 212:76-88.

Farzan F, Barr MS, Levinson AJ, Chen R, Wong W, Fitzgerald PB, Daskalakis ZJ (2010) Evidence for gamma inhibition deficits in the dorsolateral prefrontal cortex of patients with schizophrenia. Brain 133:1505-1514.

Fitzgerald PB, Fountain S, Daskalakis ZJ (2006) A comprehensive review of the effects of rTMS on motor cortical excitability and inhibition. Clin Neurophysiol 117:2584-2596.

Freund TF (2003) Interneuron diversity series: Rhythm and mood in perisomatic inhibition. Trends Neurosci 28:489-495.

Funke K, Benali A (2009) Short-latency afferent inhibition varies with cortical state in rat somatosensory cortex. Neuroreport 20:1313-1318.

Griffiths R, Norman RI (1993) Effects of anaesthetics on uptake, synthesis and release of transmitters. Br J Anaesth 71:96-107.

Hakami T, Jones NC, Tolmacheva EA, Gaudias J, Chaumont J, Salzberg M, O'Brien TJ, Pinault D (2009) NMDA receptor hypofunction leads to generalized and persistent aberrant gamma oscillations independent of hyperlocomotion and the state of consciousness. PLoS One 4:e6755.

Hara K, Harris A (2002) The anesthetic mechanism of urethane: the effects on neurotransmitter-gated ion channels. Anaesth Pharmacol 94:313-318.

Härtig W, Brauer K, Brückner G (1992) Wisteria floribunda agglutininlabelled nets surround parvalbumin-containing neurons. Neuroreport 3:869-872.

Hartmann M, Heumann R, Lessmann V (2002) Synaptic secretion of BDNF after high-frequency stimulation of glutamatergic synapses. EMBO J 20:5887-5897.

Hiscock JJ, Mackenzie L, Willoughby JO (1998) Laminar distribution of Fos/calcium-binding protein and Fos/neurofilament protein-labeled neurons in rat motor and sensory cortex after picrotoxin-induced seizures. Exp Neurol 149:373-383.

Hong LE, Summerfelt A, Buchanan RW, O'Donnell P, Thaker GK, Weiler MA, Lahti AC (2010) Gamma and delta neural oscillations and association with clinical symptoms under subanesthetic ketamine. Neuropsychopharmacology 35:632-640.

Hoshiyama M, Kakigi R (2003) Changes in somatosensory evoked responses by repetition of the median nerve stimulation. Clin Neurophysiol 114:2251-2257.

Howard A, Tamas G, Soltesz I (2005) Lighting the chandelier: new vistas for axo-axonic cells. Trends Neurosci 28:310-316.

Huang YZ, Edwards MJ, Rounis E, Bhatia KP Rothwell JC (2005) Theta burst stimulation of the human motor cortex. Neuron 45:201-206.

Jiang B, Kitamura A, Yasuda H, Sohya K, Maruyama A, Yanagawa Y, Obata K, Tsumoto T (2004) Brain-derived neurotrophic factor acutely depresses excitatory synaptic transmission to GABAergic neurons in visual cortical slices. Eur J Neurosci 20:709-718.

Kawaguchi Y, Kubota Y (1998) Neurochemical features and synaptic connections of large physiologically-identified GABAergic cells in the rat frontal cortex. Neuroscience 85:677-701.

Krieg WJ (1946) Cortical areas of the albino rat. Arch Neurol Psych 56:739.

Kullmann DM, Lamsa KP (2007) Long-term synaptic plasticity in hippocampal interneurons. Nat Rev Neurosci 8:687-699.

Kwon JS, O’Donnell BF, Wallenstein GV, Greene RW, Hirayasu Y, Nestor PG, Hasselmo ME, Potts GF, Shenton ME, McCarley RW (1999) Gamma frequency-range abnormalities to auditory stimulation in schizophrenia. Arch Gen Psychiatry 56:1001-1005.

Lamsa K, Taira T (2003) Use-dependent shift from inhibitory to excitatory GABAA receptor action in SP-O interneurons in the rat hippocampal CA3 area. J Neurophysiol 90:1983-1995.

Lewis DA, Hashimoto T, Volk DW (2005) Cortical inhibitory interneurons and schizophrenia. Trends Neurosci 6:312-324.

Lodge DJ, Behrens MM, Grace AA (2009) A loss of parvalbumin-containing interneurons is associated with diminished oscillatory activity in an animal model of schizophrenia. J Neurosci 29:2344-2354.

Lu JT, Li CY, Zhao JP, Poo MM, Zhang XH (2007) Spike-timing-dependent plasticity of neocortical excitatory synapses on inhibitory interneurons depends on target cell type. J Neurosci 27:9711-9720.

Maccabee PJ, Amassian VE, Eberle LP, Cracco RQ (1993) Magnetic coil stimulation of straight and bent amphibian and mammalian peripheral nerve in vitro: locus of excitation. J Physiol Lond 460:201-219.

Mainardi M, Landi S, Berardi N, Maffei L, Pizzorusso T (2009) Reduced 
responsiveness to long-term monocular deprivation of parvalbumin neurons assessed by c-Fos staining in rat visual cortex. PLoS One 4:e4342.

Markram H, Toledo-Rodriguez M, Wang Y, Gupta A, Silberberg G, Wu C (2004) Interneurons of the neocortical inhibitory system. Nat Rev Neurosci 5:793-807.

Michaluk J, Antkiewicz-Michaluk L, Vetulani J (2001) Conditions of application of repeated transcranial magnetic stimulation to rats may mask the effects of the treatment. Pol J Pharmacol 53:685-687.

Minchin MC (1981) The effect of anaesthetics on the uptake and release of gamma-aminobutyrate and D-aspartate in rat brain slices. Br J Pharmacol 73:681-689.

Mix A, Benali A, Eysel UT, Funke K (2010) Continuous and intermittent transcranial magnetic theta burst stimulation modify tactile learning performance and cortical protein expression in the rat differently. Eur J Neurosci 32:1575-1586.

Moliadze V, Zhao Y, Eysel U, Funke K (2003) Effect of transcranial magnetic stimulation on single-unit activity in the cat primary visual cortex. J Physiol 553:665-679.

Morris BJ, Cochran SM, Pratt JA (2005) PCP: from pharmacology to modelling schizophrenia. Curr Opin Pharmacol 5:101-106.

Paxinos G, Watson C (1986) The rat brain in stereotaxic coordinates. San Diego: Academic.

Petrasch-Parwez E, Nguyen HP, Löbbecke-Schumacher M, Habbes HW, Wieczorek S, Riess O, Andres KH, Dermietzel R, Von Hörsten S (2007) Cellular and subcellular localization of Huntingtin aggregates in the brain of a rat transgenic for Huntington disease. J Comp Neurol 501:716-730.

Petrasch-Parwez E, Habbes HW, Weickert S, Löbbecke-Schumacher M, Striedinger K, Wieczorek S, Dermietzel R, Epplen JT (2004) Finestructural analysis and connexin expression in the retina of a transgenic model of Huntington's disease. J Comp Neurol 479:181-197.

Pratt JA, Winchester C, Egerton A, Cochran SM, Morris BJ (2008) Modelling prefrontal cortex deficits in schizophrenia: implications for treatment. Br J Pharmacol 153:S465-S470.

Ragert P, Becker M, Tegenthoff M, Pleger B, Dinse HR (2004) Sustained increase of somatosensory cortex excitability by $5 \mathrm{~Hz}$ repetitive transcranial magnetic stimulation studied by paired median nerve stimulation in humans. Neurosci Lett 356:91-94.

Roopun AK, Cunningham MO, Racca C, Alter K, Traub RD, Whittington MA (2008) Region-specific changes in gamma and beta2 rhythms in NMDA receptor dysfunction models of schizophrenia. Schizophr Bull 34:962-973.

Rotem A, Moses E (2006) Magnetic stimulation of curved nerves. IEEE Trans Biomed Eng 53:414-420.

Rozov A, Burnashev N, Sakmann B, Neher E (2001) Transmitter release modulation by intracellular $\mathrm{Ca}^{2+}$ buffers in facilitating and depressing nerve terminals of pyramidal cells in layer $2 / 3$ of the rat neocortex indicates a target cell-specific difference in presynaptic calcium dynamics. J Physiol 531:807-826.

Sakai T, Oshima A, Nozaki Y, Ida I, Haga C, Akiyama H, Nakazato Y, Mikuni M (2008) Changes in density of calcium-binding-protein-immunoreactive GABAergic neurons in prefrontal cortex in schizophrenia and bipolar disorder. Neuropathology 28:143-150.

Schwaller B (2009) The continuing disappearance of "pure" $\mathrm{Ca}^{2+}$-buffers. Cell Mol Life Sci 66:275-300.
Schwaller B, Dick J, Dhoot G, Carroll S, Vrbova G, Nicotera P, Pette D, Wyss A, Bluethmann H, Hunziker W, Celio MR (1999) Prolonged contractionrelaxation cycle of fast-twitch muscles in parvalbumin knockout mice. Am J Physiol 276:C395-403.

Sinclair MD (2003) A review of the physiological effects of alpha2-agonists related to the clinical use of medetomidine in small animal practice. Can Vet J 44:885-897.

Skoglund TS, Pascher R, Berthold CH (1997) The existence of a layer IV in the rat motor cortex. Cereb Cortex 7:178-180.

Stagg CJ, Wylezinska M, Matthews PM, Johansen-Berg H, Jezzard P, Rothwell JC, Bestmann S (2009) Neurochemical effects of theta burst stimulation as assessed by magnetic resonance spectroscopy. J Neurophysiol 101:2872-2877.

Sun QQ (2009) Experience-dependent intrinsic plasticity in interneurons of barrel cortex layer IV. J Neurophysiol 102:2955-2973.

Thickbroom GW (2007) Transcranial magnetic stimulation and synaptic plasticity: experimental framework and human models. Exp Brain Res 180:583-593.

Tokimura H, Di Lazzaro V, Tokimura Y, Oliviero A, Profice P, Insola A, Mazzone P, Tonali P, Rothwell JC (2000) Short latency inhibition of human hand motor cortex by somatosensory input from the hand. J Physiol 523:503-513.

Trippe J, Mix A, Aydin-Abidin S, Funke K, Benali A (2009) Theta burst and conventional low frequency rTMS differentially affect GABAergic neurotransmission in the rat cortex. Exp Brain Res 199:411-421.

Tropea D, Kreiman G, Lyckman A, Mukherjee S, Yu H, Horng S, Sur M (2006) Gene expression changes and molecular pathways mediating activity-dependent plasticity in visual cortex. Nat Neurosci 9:660-668.

Tsumoto T (1992) Long-term potentiation and long-term depression in the neocortex. Prog Neurobiol 39:209-228.

van Brederode JF, Helliesen MK, Hendrickson AE (1991) Distribution of the calcium-binding proteins parvalbumin and calbindin-D28k in the sensorimotor cortex of the rat. Neuroscience 44:157-171.

Vierling-Claassen D, Siekmeier P, Stufflebeam S, Kopell N (2008) Modeling GABA alterations in schizophrenia: a link between impaired inhibition and altered gamma and beta range auditory entrainment. J Neurophysiol 99:2656-2671.

Vreugdenhil M, Jefferys JG, Celio MR, Schwaller B (2003) Parvalbumindeficiency facilitates repetitive IPSCs and gamma oscillations in the hippocampus. J Neurophysiol 89:1414-1422.

Weiler E, Benali A (2005) Olfactory epithelia differentially express neuronal markers. J Neurocytol 34:217-240.

Weiser M, Bueno E, Sekirnjak C, Martone ME, Baker H, Hillman D, Chen S, Thornhill W, Ellisman M, Rudy B (1995) The potassium channel subunit Kv3.1b is localized to somatic and axonal membranes of specific populations of CNS neurons. J Neurosci 15:4298-4314.

Weissman JD, Epstein CM, Davey KR (1992) Magnetic brain stimulation and brain size: relevance to animal studies. Electroencephalogr Clin Neurophysiol 85:215-219.

Winsky L, Kuźnicki J (1996) Antibody recognition of calcium-binding proteins depends on their calcium-binding status. J Neurochem 66:764-771.

Zilles K (1985) The cortex of the rat—a stereotaxic atlas. Berlin: Springer.

Zilles K, Wree A (1995) Cortex: areal and laminar structure. In: The rat nervous system (Paxinos G, ed), pp 649-685. San Diego: Academic. 